\title{
Efficacy evaluation of a full-scale response to intervention program for enhancing student reading abilities in a Swedish school context
}

\author{
Camilla Nilvius $^{1}$ (D) $\cdot$ Idor Svensson $^{2}$ (D)
}

Accepted: 2 December 2021 / Published online: 20 December 2021

(c) The Author(s) 2021

\begin{abstract}
Reading abilities in Swedish students have declined in recent decades. The current study examined the effectiveness of a full-scale three-tier Response to Intervention (RtI) model designed to improve reading skills in Swedish students. Participants were grade 2 students in a primary school setting. A quasi-experimental between-group design was used to examine treatment effects. The RtI experimental group $(n=11)$ and comparison group $(n=11)$ were monitored longitudinally over 2.5 years. The interventions included specialized instruction on decoding and reading comprehension. The comparison group received treatment as usual. After the intervention, the number of students in need of support in the experimental RtIgroup was reduced from six to one. Furthermore, decoding and reading comprehension improved in the experimental group relative to the comparison group; however, the results were not significant. The standard deviation in the experimental group was smaller than that in the comparison group for all follow-up measures. The intervention effect was sustained after one and a half year in most of the students who had responded to the intervention. In addition, the participating teachers mostly appreciated the RtI-model. These preliminary findings suggest that the RtI model possibly can enhance reading skills in Swedish students; however, more research is needed. Implications for using the RtI model are discussed.
\end{abstract}

Keywords Primary education · Reading $\cdot$ Response to intervention · Quasiexperimental design

Camilla Nilvius

Camilla.nilvius@1nu.se

Idor Svensson

Idor.svensson@lnu.se

1 Department of Pedagogy and Learning, Linnaeus University, Universitetsplatsen 1, 35252 Växjö, Sweden

2 Department of Health and Life Science, Linnaeus University, 35252 Växjö, Sweden 


\section{Introduction}

The first years of school are particularly important for the development of competent reading. Acquiring the ability to read fluently in the primary school years greatly facilitates students' future knowledge acquisition (Francis et al., 1996). Early identification of reading difficulties and evidence-based interventions to prevent these are important (Lovett et al., 2017). However, the reading abilities of Swedish students have declined in recent decades. The identification of challenges and provision of support currently occurs most frequently during the later years of Swedish compulsory schooling (students aged 13-15 years) (Government Offices of Sweden, 2017). Thus, many students do not receive adequate support during the early school years, increasing the overall difficulty experienced by students throughout their school years. The Swedish Schools Inspectorate (Skolinspektionen, 2014) has reported that many schools lack routines and organization to support teachers in the identification of reading difficulties, as well as training regarding appropriate interventions and support for students. Indeed, teachers and schools appear to take a "wait-and-see" approach to reading difficulties. To address this problem, a new law has been proposed: "Läsa, skriva, räkna garanti" [Read, write, count guarantee] (Läsa, skriva, räkna garantin, 2016). However, a recent report from the Swedish Schools Inspectorate (Skolinspektionen, 2020a) stated that the guarantee has not functioned as intended. One-third of the schools surveyed had not completed all the mandatory activities during the autumn term. Half of the schools had not conducted any additional assessments for students with signs of reading difficulties. Furthermore, half of the schools failed to plan consultations with staff members who were special needs experts (Skolinspektionen, 2020a). Therefore, the guarantee appears insufficient for addressing reading difficulties in Swedish public schools. Accordingly, further efforts to encourage the early identification of reading difficulties and efficient interventions to prevent them are needed. Teachers in Swedish public schools are given material to conduct qualitative assessments of reading progress in students in grade 1 (mandatory) and grades 2 and 3 (optional) (Skolverket [Swedish National Agency for Education], 2019b). However, norm-based screening to supplement these qualitative assessments is not mandatory in Sweden.

In contrast to Sweden, the United States has focused on identifying students who need extra support, with frameworks to assist teachers and students (Fuchs \& Fuchs, 2006). Since the beginning of the 21 st century and the reauthorization of the No Child Left Behind" Act, multitiered frameworks to support struggling students have been implemented in schools across the United States (Denton, 2012). Such frameworks aim to identify students who need support, enabling teachers to intervene (Bjorn et al., 2018; Fuchs \& Fuchs, 2006). The most well-known multitiered support system is the Response to Intervention (RtI) system, which has been found to reduce the percentage of students referred to special education from 9 to $1.5 \%$ (Grosche \& Volpe, 2013). Despite this success, such multitiered support systems are relatively rare worldwide, although their use is increasing. Previous research has demonstrated the efficiency of full-scale RtI models in 
identifying students in need and providing appropriate interventions. Therefore, such systems may be applicable in a Swedish school context.

\section{Background: response to intervention (RtI) and multitiered systems of support}

RtI is a tiered framework developed with two purposes: to provide struggling students with early and efficient instruction and to provide a valid means of assessing learner needs (Fuchs \& Fuchs, 2006). RtI can also be described as a preventive and proactive system, in contrast to education systems in which students must first fail before receiving support (i.e., a "wait-to-fail" approach) (Fuchs \& Fuchs, 2006). The RtI framework is often referred to as a tiered model of academic and behavioral support. It usually includes three tiers, and its overall aim is to prevent learning difficulties. The main objective of the model is to gradually increase support efforts; for example, by teaching students in smaller groups, offering more time for learning, and, if needed, providing students with individually designed intensive interventions. Monitoring student development is essential throughout the application of the whole model (Stecker et al., 2017). In the first tier, evidence-based classroom instruction is provided to all students, and screening measures are used to monitor student development closely. Monitoring serves to identify students who may not respond adequately to classroom instructions and fail to meet expected standards. In Tier 2, students who have not responded to the instructions received in Tier 1 receive additional interventions in a smaller group setting. Tier 2 comprises more intense interventions for struggling students, with frequent monitoring of student progress and evidence-based interventions. The Tier 2 monitoring results may indicate that some students require more individualized support and interventions. These students are admitted to Tier 3, which involves evidence-based interventions, often via oneto-one instruction, that are more individualized, intense, and often longer in duration. Progress monitoring in Tier 3 is conducted every week or every second week. Tier 2 and 3 interventions are delivered in addition to the general curriculum, not as replacements (Denton, 2012; Fuchs \& Fuchs, 2006). The RtI model can help a large proportion of the student group. Therefore, the RtI model may reduce immediate or unnecessary referrals for special education while providing students with increased support through tiered interventions (Grosche \& Volpe, 2013).

There is much empirical support for the efficiency of interventions using the RtI model (Gersten et al., 2020; Wanzek et al., 2016, 2018). Because the model was established in the United States, most studies demonstrating its effectiveness have been conducted in that country. Many studies have examined the effectiveness of reading interventions in different RtI tiers and reported positive results. Specifically, researchers have found positive effects for Tier 1 (Al Otaiba et al., 2011; Clarke et al., 2011), Tier 2 (Case et al., 2014; Clarke et al., 2016; Gersten et al., 2020; Kerins et al., 2010), and Tier 3 interventions (Compton et al., 2012; Denton et al., 2013; Fuchs et al., 2008).

One criticism directed at RtI is that students often get "more of the same" types of support efforts and that it is unclear what separates each tier (Gilbert et al., 2013; Reynolds \& Shaywitz, 2009; Wanzek \& Vaughn, 2008). RtI research with long 
intervention periods, approximately 100 sessions in Tier 2 or 3, has demonstrated positive outcomes (Denton et al., 2014; Simmons et al., 2011). However, some studies with intervention periods of approximately 30 sessions have also reported positive outcomes, suggesting that short-term supplemental reading interventions are just as efficient (Case et al., 2014; Pericola Case et al., 2010). Long-term interventions can be demanding for teachers and students (Fälth et al., 2013). Researchers also disagree on which tier is appropriate for a student with early signs of reading difficulties; that is, whether the student should first receive low-intensity measures in a classroom setting in Tier 1 or immediately receive intensive interventions in Tier 2 or 3 (Al Otaiba et al., 2014; Vaughn et al., 2010). Vaughn et al. (2010) claims that starting with more intensive interventions immediately produces a greater beneficial effect. Despite the reported efficiency of RtI programs in the different tiers described above, few experimental studies have examined the effectiveness of the full RtI model (i.e., with all three tiers) (Gersten et al., 2009; Hill et al., 2012). Thus, a complete evaluation of the model is needed (Denton, 2012). Balu et al. (2015) conducted a national evaluation of the RtI model using impact analyses and descriptive analyses based on survey data. However, their study was limited by its regression discontinuity design and focus on evaluation (Fuchs \& Fuchs, 2017).

Educators worldwide are increasingly using the RtI model. A similar multitiered framework has been used in Finland since 2010 (Bjorn et al., 2018), and a comparative framework was also implemented in the Netherlands (Scheltinga et al., 2010). However, multitiered systems such as the RtI model have not previously been implemented or scientifically examined in a Swedish school context. To address this in the present study, we investigated the possibility that a multitiered full-scale RtI model could provide an effective framework for identifying students with reading difficulties and the provision of appropriate interventions in Sweden.

\section{Purpose and research questions}

This study examined the efficacy of a full-scale RtI model implemented in a Swedish school context in terms of improvements in student decoding and reading comprehension. We addressed the following research questions:

- How do word decoding and reading comprehension differ between students who underwent RtI reading interventions and students who underwent treatment as usual (TAU)?

- What are the teacher impressions of the RtI model?

\section{Method}

We examined the use of a full-scale RtI model in a Swedish primary school setting with a quasi-experimental design. The between-group design examined the efficacy of the RtI model with an experimental group matched (on decoding and gender) to a comparison group receiving Treatment as Usual (TAU). A researcher recruited 
participants from the students and teaching staff at a school willing to participate in the study and commit to conducting monitoring and interventions according to the RtI model during a 1-year period. The efficacy of the RtI model was examined according to progressive changes in reading ability in 11 students. The longitudinal study design enabled us to monitor changes in student reading ability across RtI Tiers 1-3 during grade 2, with follow-up assessments at half a year and one and a half year. Students were deemed to be "at-risk" in the present study if they received a score below the 30th percentile or a stanine score of 3 on reading comprehension tests.

Students $(n=11)$ in the RtI experimental group were matched to students in a comparison group $(n=11)$ from the same school district. Pre-intervention matching was conducted using a composite score generated from the percentile of non-word and sight word reading test scores and gender (the groups were fully matched in terms of gender). The two cohorts were similar in decoding ability, as indicated by initial pre-intervention composite scores. Test data were primarily collected to enable teachers to monitor student development and to take adequate measures to teach the students at an appropriate level in the RtI tiers. Furthermore, the test data also reflected student responsiveness to the interventions within the RtI model. Both the experimental and comparison group completed pre-intervention, post-intervention, half year, and one-and-a-half-year follow-up assessments.

Students were invited to participate in the study regardless of their personal characteristics or challenges. After receiving information about the study, all students agreed to participate, and their parents provided written informed consent. The present study received ethical approval from Etikprövningsnämnden [Ethical Review Board] before the start of the project (D.nr 2017/412-31). The RtI model was implemented at the comparison school after the project was complete.

\section{Participants}

The study was conducted in two schools (K-6) in a school district in southern Sweden with an average socio-economic index number of 110. The National Agency calculates the socio-economic index for education, and approximately average for Swedish schools is 100 . The index thus reflects the probability for the students at a school to achieve different grading results. A low socio-economic index for a school means that the school generally has a favorable condition for a good result and a high index signals that the school has an unfavorable condition. 110 is close to the mean index number.

The selected class for the RtI group consisted of 11 grade 2 students, four boys, and seven girls. Two part-time teachers shared responsibility for the class. The average amount of teaching experience among the teachers in the RtI group was 5.5 years. The class also had a special needs teacher who was involved in the interventions. All three staff members took part in teacher discussions, which the first author of this study also attended. The class recruited for comparison comprised 11 students in grade 2 in the same school district. The students in the matched comparison group comprised four boys and seven girls. The teachers in the comparison 
group had an average of 2.5 years of teaching experience, and there was a special needs teacher attached to the class. Both the RtI group and the comparison group had two students for whom Swedish was their second language.

\section{Materials}

According to the Simple View of Reading (SVR) theory (Gough \& Tunmer, 1986), decoding is an essential part of reading. Therefore, we administered a decoding test to assess this ability. The LäSt is a standardized test for evaluating and diagnosing basic reading skills in students in grades 1-6 (Elwér et al., 2016). Among other tests, the LäSt includes two tests in which students are asked to decode words: one is for non-words, and the other is for sight words. Each test has two parts (versions A and B) in which students are asked to read words out loud for $45 \mathrm{~s}$. The decoding test is administered individually, and each test takes a maximum of $5 \mathrm{~min}$ to complete. The raw score is the total number of accurately read words minus the number of errors. The test-retest reliability for the LäSt is 0.97 in children aged 6-9 years. The decoding tests (non-word and sight words) were conducted three times within one week at four different time points: the pre-intervention period (baseline), post-test, half year follow-up, and at one and a half year follow-up to obtain a stable and consistent result (Cirino et al., 2002). The mean of the three test scores was calculated and used to monitor student development and assignment to different tiers and interventions. Because the test took approximately $5 \mathrm{~min}$ to complete, repeated testing was not considered demanding for the students.

Reading comprehension is essential according to the SVR theory (Gough \& Tunmer, 1986). To assess reading comprehension, we used the Vilken bild är rätt? [Which picture is the correct one?] test (Lundberg, 2001). The test is standardized with national norms and assesses reading comprehension level in $10 \mathrm{~min}$. It assesses accuracy, flow, and confidence in reading as well as a student's ability to read and understand short texts. The student reads one or two sentences and decides which of four pictures precisely fits the meaning of the text. The raw score is the total number of correctly marked pictures minus the number of errors. Norms are only available for grades $2-3$. The test-rest reliability is 0.88 .

In addition to the quantitative tests, we collected field notes from the teacher meetings, which contained the teachers' reflections on implementing the RtI model. The field notes were considered as descriptive data and were not qualitatively analyzed.

\section{Procedure}

Prior to the start of the study, the first author $(\mathrm{CN})$ conducted a meeting with the school principal, the two class teachers, and the special needs teacher working with the RtI group. The purpose of the meeting was to describe the project to the staff members and discuss the structure and feasibility of the RtI model. Furthermore, we provided the teachers with evidence-based Swedish reading lessons from the "Kunskapsöversikt om läs- och skrivundervisning för yngre elever" [Overview of 
reading and writing instruction for young students] (Taube et al., 2015). These evidence-based recommendations formed the basis of instruction in all three tiers of the intervention, and the teacher's selected methods and materials aligned with these recommendations. The recommendations include explicit and systematic instruction of grapheme-phoneme correspondence, counteraction of word guessing in reading (secure correct decoding), repeated reading to obtain fluency (as a motivational activity), implicit and explicit word activities, and reading comprehension strategies. These elements form part of a balanced reading program in which students also illustrate and dramatize the texts they have read. The project plan was presented and discussed. Opportunities for teacher group discussions and test dates were set according to the following structure (see Fig. 1).

The first author of this paper $(\mathrm{CN})$ held eight teacher group discussions during the project. Student progress in decoding and reading comprehension was frequently monitored throughout the different tiers. The discussion sessions enabled the teachers to consider further interventions and make decisions about the admission of students to the different tiers according to each student's development and responses to the instruction. The teachers' observations and classroom experiences were compared with the assessment test results. Decisions about which tier students should be in were made according to specific cutoff values: students with a score below the $30^{\text {th }}$ percentile in the decoding test and a stanine score of 3 in the reading comprehension test were admitted to the next tier. The teachers also made adjustments to the upcoming interventions to further enhance student reading abilities. In the last teacher group discussion, the teachers descriptively summarized their experiences of the RtI-model. Field notes served as descriptive data about the teachers' reflections on the interventions and the RtI-model. The teachers also documented their materials and methods for each tier using logbooks. The teachers in the comparison group documented the books, materials, and teaching methods used during the project period.

The research project involved careful monitoring of the students in the RtI group. One author $(\mathrm{CN})$ conducted all the screening tests during the RtI project to increase observer reliability. The RtI is usually a three-stage model (Denton, 2012; Fuchs \&

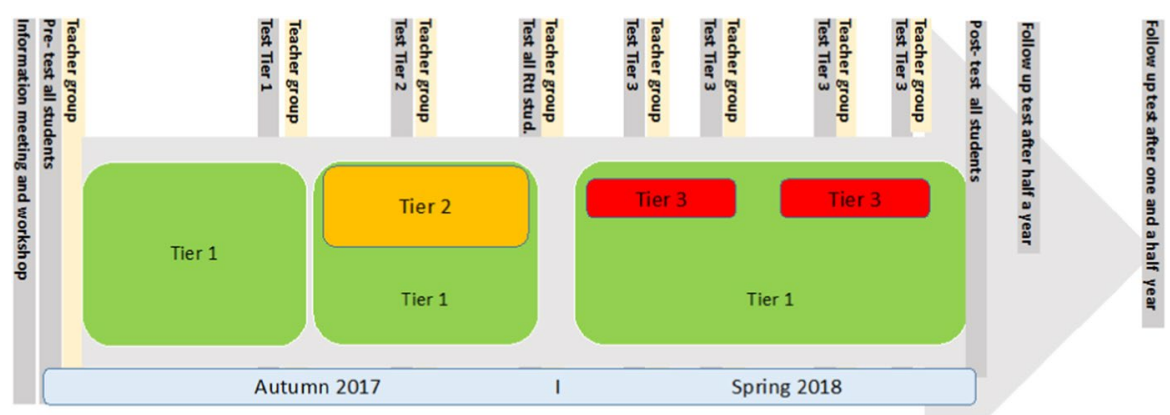

Fig. 1 Visual representation of the RtI project 
Fuchs, 2006), and we used a three-tier model in the present study. Each student's progress was monitored, and a staged series of interventions to improve reading skills was carried out in Tiers 1-3 (see Fig. 2).

The 11 students in the RtI group received ordinary Swedish lessons in a regular classroom setting as Tier 1 of the model between August and October. Tier 1 instruction was then continuously carried out throughout the project period for students who did not participate in Tiers $2-3$. Tier 2 instruction comprised small-group instruction, supplementary to Tier 1 instruction, in groups of three students for seven weeks at the end of the autumn semester. Tier 2 instruction comprised two $40 \mathrm{~min}$ sessions per week delivered by the special needs teacher in close collaboration with the class teachers. The lesson environment was physically similar to that of the ordinary classroom setting. At the beginning of the spring semester, all the students in the RtI group completed the entire test battery. A group discussion with the teachers was conducted to discuss the RtI students' progress and consider further interventions, including possible Tier 3 interventions for students who had not responded adequately to the Tier 2 interventions. Three students were initially admitted to Tier

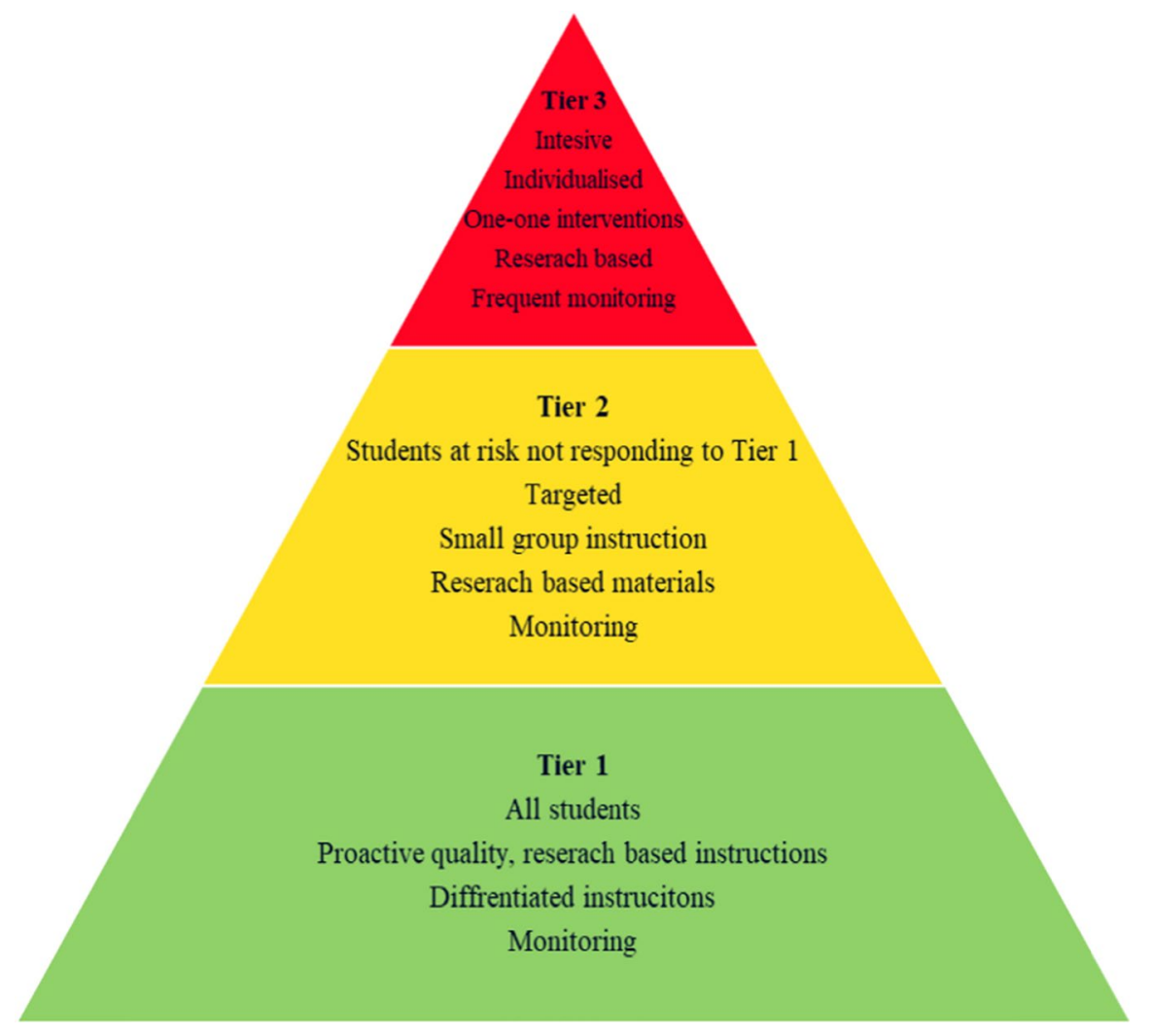

Fig. 2 The RtI model used in the present project. Inspired of RtI-models at: https://impactofspecialneeds. weebly.com/RtI.html 
3 reading interventions. Tier 3 instruction comprised four 30 min sessions per week for four weeks. The interventions were individually designed and comprised one-toone instruction. These were delivered in addition to the ordinary Tier 1 Swedish lessons. Two of these students underwent a second period of Tier 3 interventions with the same intensity (four 30 min sessions per week for four weeks) during the second half of the spring semester.

\section{Interventions in different tiers}

\section{Tier 1 interventions}

Tier 1 comprised general evidence-based instruction delivered in a classroom setting as differentiated lessons for students identified in the pre-intervention test as having decoding or reading comprehension difficulties. The instruction was in accordance with recommendations from Taube et al. (2015). The Swedish lessons were based on the reading material "Diamantjakten" [Diamond hunt] (Felth Sjölund, 2012). Students received reading lessons once every week using this textbook. The same texts were read several times, both in school and as homework, to enhance reading fluency. Repeated reading of the same text was used to motivate the students, as it provided the opportunity to evaluate their achievement of reading fluency. In addition, the students received explicit instruction on letter and sound correspondence when they were still in the early stages of learning. Systematic instruction of the relationship between graphemes and phonemes in an alphabetic writing system is fundamental (Castles et al., 2018). The Fonomix material, inspired by Lindamood, was used (Löwenbrand-Jansson, 2018). The Fonomix program is a phonological and multisensory reading method that connects the visual, auditory, and kinesthetic senses and concretizes the phoneme-grapheme connection. Students were trained on decoding and reading fluency using Wendick IntensivLäsning [Wendick Intensive Reading], a decoding-specific material (Wendick, 2018). Reciprocal teaching was used to develop reading comprehension strategies (Palinscar \& Brown, 1984). In addition to the explicit teaching methods described, the teachers arranged a balanced reading program with stimuli to enhance student speech development, motivation to read, and ability to formulate their ideas in writing. Students illustrated and dramatized their impressions of a fiction book. The Swedish curriculum includes assistive technology (AT). AT was, therefore, a part of the ordinary classroom setting and was presented as part of the Tier 1 instruction.

\section{Tier 2 interventions}

The Tier 2 interventions were evidence-based, with recommendations from Taube et al. (2015). The special needs teacher delivered the Tier 2 interventions. Two intervention groups with three students in each group were set up according to the results of the baseline Tier 1 screening tests. One group primarily focused on decoding difficulties, and the other group addressed reading comprehension. In the "decoding group," the teacher focused on letter-sound correspondence using Fonomix program 
settings specific to each student's needs. The students practiced decoding and synthesis using reading lists (Wendick, 2018). Repeated reading was conducted using texts with a word complexity level tailored to each student's needs. Students practiced decoding using the "Läshoppet" [Read jump] book series (Natur \& Kultur, 2020). The other intervention group focused solely on reading comprehension. The teacher and students read a fiction book; the students used reciprocal teaching strategies (Palinscar \& Brown, 1984). Monitoring took place in the middle and end of the Tier 2 instruction. All students in the comprehension group surpassed the cutoff point of a stanine score of 3 in terms of reading comprehension and a decoding score in the 30th percentile and were thus referred back to the classroom setting. However, students in the decoding group still required interventions, which primarily involved decoding and secondarily concerned reading comprehension.

\section{Tier 3 interventions}

As with Tiers 1 and 2, the Tier 3 interventions were based on empirical evidence. The special needs teacher managed the interventions. One-to-one instruction was conducted with three students. Compared with the Tier 2 instruction, the interventions were even more individualized to each student's needs. Tailored and individualized interventions in Tier 3 followed the basic idea of the RtI framework. For example, one student who was still not confident about the g-k and v-f graphemephoneme correspondences practiced with the Fonomix material.

In contrast, another student who mixed up the vowels e-ä and o-å practiced that with the Fonomix material. However, the interventions primarily focused on enhancing each student's confidence in letter-sound correspondence and decoding ability. Repeated reading was also conducted using texts with individualized and tailored levels of word complexity, so that each student would be able to decode words. The texts were taken from "Läshoppet" [Reading jump] (Natur \& Kultur, 2020). Reciprocal teaching strategies were now added to enhance reading comprehension because the students' decoding ability had increased. The end of the intervention lesson included approximately $5 \mathrm{~min}$ of the reading game Svenska Trugs [Swedish Trugs] (Häggström \& Frylmark, 2010). Monitoring took place in the middle of the Tier 3 instruction period and after the end of the intervention. At the end of the Tier 3 interventions, all students had reached the cutoff level for decoding (in percentile composite score), but one student remained below the cutoff for reading comprehension.

\section{Implementation adherence}

The teachers used logbooks to document their activities during the RtI program, and these served as a record of implementation adherence in terms of (a) the prescribed number and (b) the length of interventions for the different tiers. The logbook notes were considered in the teacher group discussions. To enhance participant validation, 
the study informants (two teachers and one special needs teacher) were allowed to correct any incorrect perceptions that the researcher had recorded in the field notes.

\section{Comparison group}

The comparison group underwent TAU. Their reading instruction was based on the Diamantjakten [Diamond hunt] reading material (Felth Sjölund, 2012). The comparison group had reading lessons with this textbook once every week. The same texts were read several times, both in school and as homework, to enhance reading fluency. Reciprocal teaching (Palinscar \& Brown, 1984) was used to practice reading comprehension strategies. Groups of students read the same fiction book and completed exercises using reading comprehension strategies. The students also wrote book reviews, read non-fiction books, and wrote non-fiction texts. During class, the students also engaged in group discussions about different books. The class teachers delivered all instructions. Monitoring occurred twice during the year and was conducted using qualitative national assessment material from the Swedish National Agency for Education (Skolverket, 2019b). Assistive technology was available in the classroom. All students were included in the ordinary classroom setting, and no students received extra support or interventions from the special needs teachers, except for two students who completed additional 20 min reading training sessions once per week for six weeks with the special needs teacher during spring 2018.

\section{Similarities and differences between the instruction given in the RtI and TAU conditions}

Both groups read the "Diamantjakten" [Diamond hunt] reading material (Felth Sjölund, 2012), used reciprocal teaching methods (Palinscar \& Brown, 1984), and had access to assistive technology in the classroom. Regarding differences between the conditions, the students in the RtI condition received explicit instruction about letter-sound correspondence, practiced decoding using reading lists, and completed repeated reading of texts in lessons and tier-based interventions that were not offered to the comparison group. Monitoring in the RtI group was frequently conducted with norm-based screening materials. Interventions were provided in Tier 2 and Tier 3 settings for students with scores on or below the 30 th percentile or a stanine score of 3. Monitoring in the comparison group took place twice during the year using national qualitative assessment materials. Interventions were minor; specifically, they were only provided to two students who received one 20 -min session per week for six weeks. 


\section{Statistical analysis}

We used a between-group design to determine whether the students in the RtI group exhibited greater reading development due to the interventions compared with students in the comparison condition. We also assessed follow-up test scores collected after the RtI project. Descriptive statistics were calculated. Effect sizes for change scores were calculated, and boxplots and individual trajectories of growth curves were generated to visualize the data distribution.

\section{Results}

\section{Statistics, data analysis, and general effects of the intervention}

We used a quasi-experimental between-group design to address our first research question, which concerned how word decoding and reading comprehension performance would differ between students in the RtI group and those in the TAU group. The test battery included a decoding test (LäSt) with non-word and sight word reading. We calculated a composite score from the percentiles of the non-word reading test and sight word reading test scores. A composite score percentile of 30 was used as the decoding ability cutoff for the matching procedure and to determine which students required interventions. We used $t$-tests to compare the pre-intervention means, examining differences between the student outcomes in the RtI and TAU groups. Complete data were available for 11 students in each of the two groups. Levene's test confirmed the equality of variances in the samples $(p>0.05)$. The paired $t$-tests showed no significant between-group differences on the pre-test. The mean scores, standard deviation, and minimum, maximum, and median for the baseline pre-intervention, post-intervention, half a year, and one-and-a-half-year follow-up probes are shown for descriptive purposes. Furthermore, we calculated the effect size between groups on post-intervention, half year, and one-and-a-half-year follow-up data. Hedges' $g$ was chosen, as the number of group participants was small. These results are shown in Table 1.

Table 1 shows descriptive statistics for the RtI group and comparison group. The dataset is also visualized in a box plot (see Fig. 3).

Table 2 shows the results for non-word reading, sight word reading, and reading comprehension. The results of the three tests in the test battery are presented in raw scores with means and standard deviations for pre-, post-, half year, and oneand-a-half-year follow-up conditions. The independent sample $t$-test showed no significant between-group differences on the one-and-a-half-year follow-up test after a Bonferroni correction for multiple tests was conducted, an adjusted alpha level of 0.016 per test $(0.05 / 3)$. However, when a one-tailed t-test was performed on the one and a half year follow-up, the non-word reading test was significant $(t(20)=2.154$, $p=0.03 / 2 p=0.015$ ). A one-tailed test might be more representative to avoid type II error since the intervention phase was expected to be positive (Rack et al., 1992; SBU, 2014; Svensson \& Jacobson, 2006). 


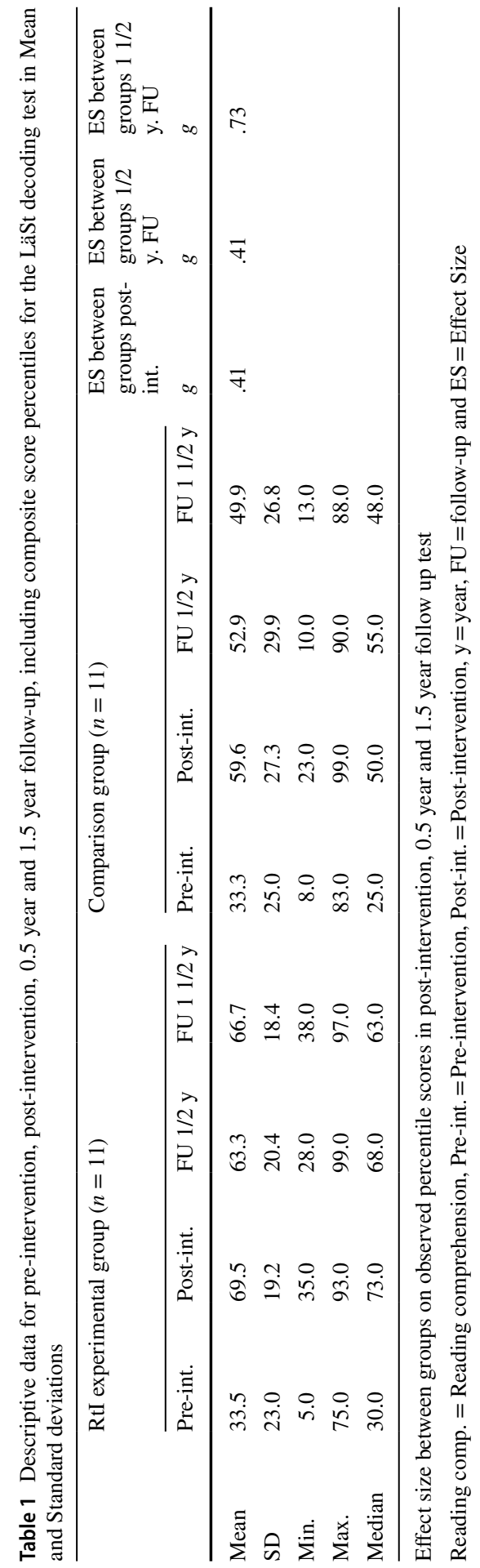




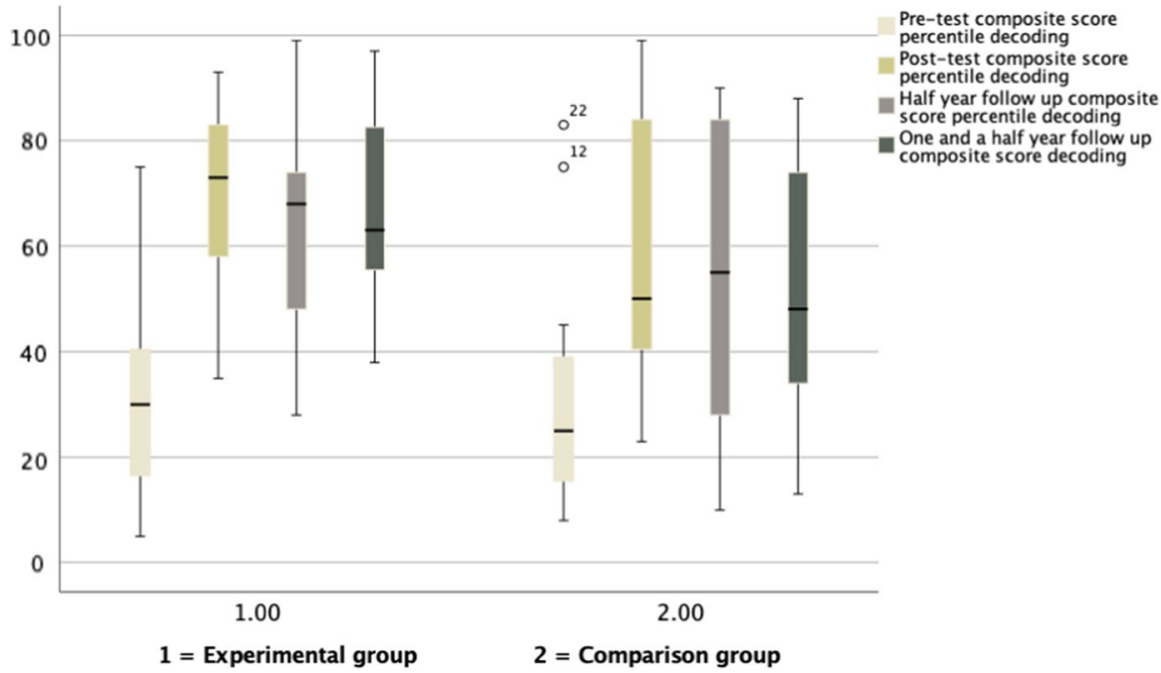

Fig. 3 Boxplot showing decoding composite scores in percentile

Figures 4, 5 and 6 show the trajectories of student progression in decoding and reading comprehension in the experimental and comparison groups during the project.

Table 2 shows the non-word reading, sight word reading, and reading comprehension results for all conditions. The results are presented in raw scores with means and standard deviations for pre-, post-, half year, and one-and-a-half-year follow-up conditions. Effect sizes are computed on observed scores between groups on conditions.

Table 2 demonstrates favorable development in the RtI group on all measures. The standard deviation was higher in the comparison group for all tests at oneand-a-half-year follow-up measure. The effect size for non-word reading was high, and the effect sizes for sight word reading and reading comprehension were moderate. However, after the Bonferroni correction, none of the tests were significant between the groups.

Figure 4 shows that all the students in the RtI group exhibited rapid development between the pre-intervention and post-intervention periods and that they all achieved raw scores above the cutoff of the $30^{\text {th }}$ percentile one and a half year after the intervention. Several students in the comparison group showed irregular development, and three were under cutoff at a one-and-a-half-year follow-up test. The distribution among these students was greater than that in the RtI group.

As shown in Fig. 5, the two groups showed relatively equal development between the pre-and post-intervention periods. However, at the one-and-a-halfyear follow-up test, four students in the comparison group exhibited somewhat tenuous development, whereas only one student from the RtI group was below the cutoff point. The reference line represents the norm of the raw score for grade 4 students just above the 30 th percentile. 


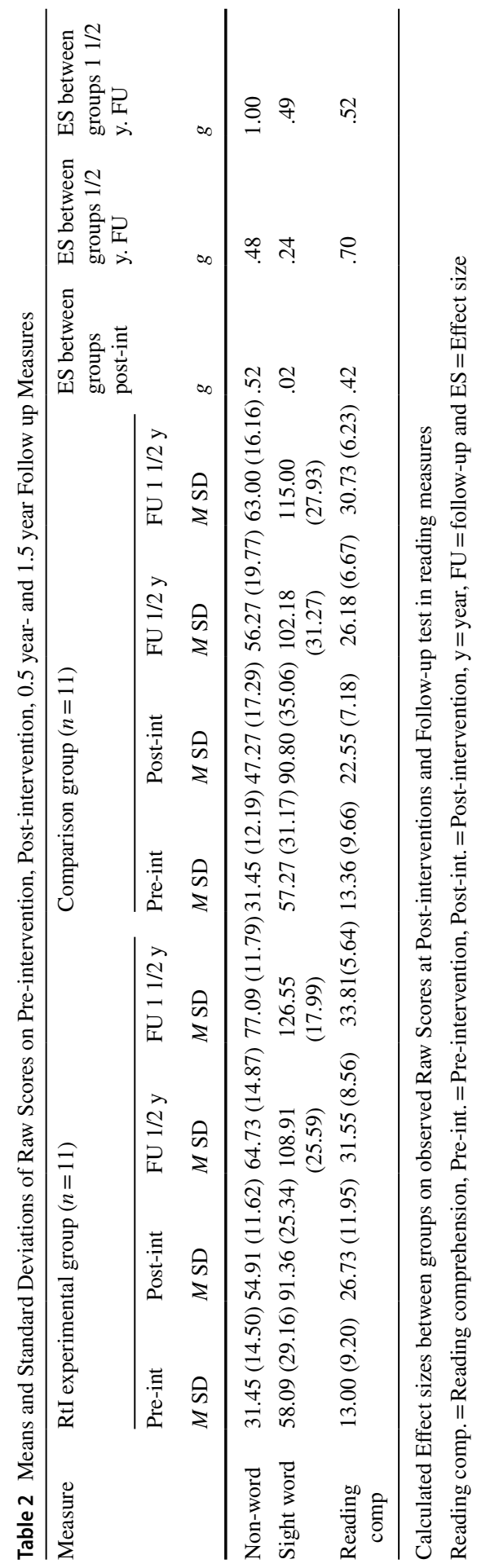




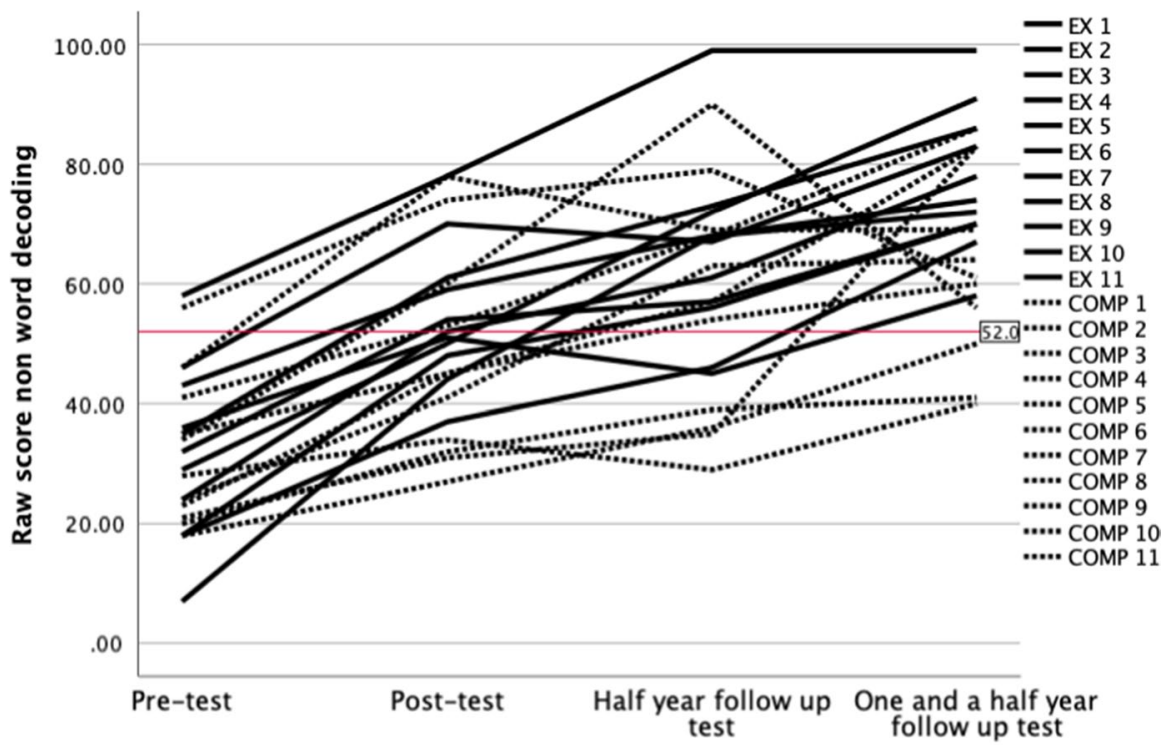

Test occations

Fig. 4 Developmental trajectories for non-word reading in the experimental and comparison groups

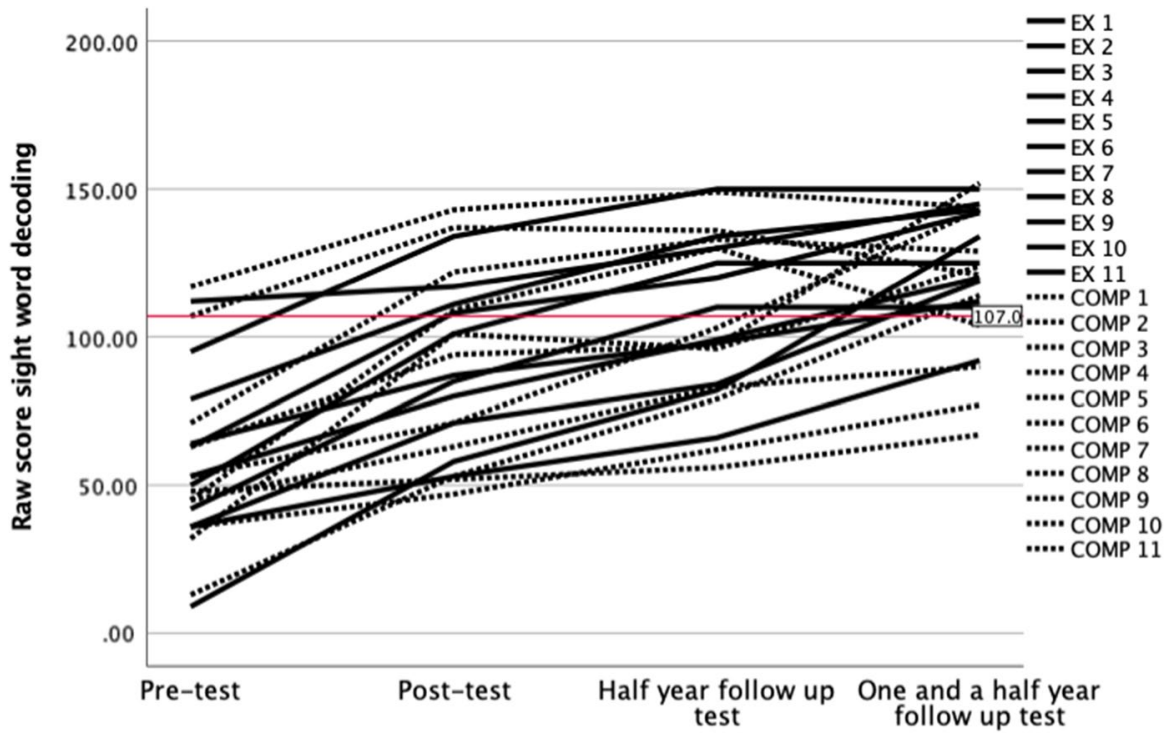

\section{Test occasions}

Fig. 5 Developmental trajectories for sight word reading in the experimental and comparison groups 


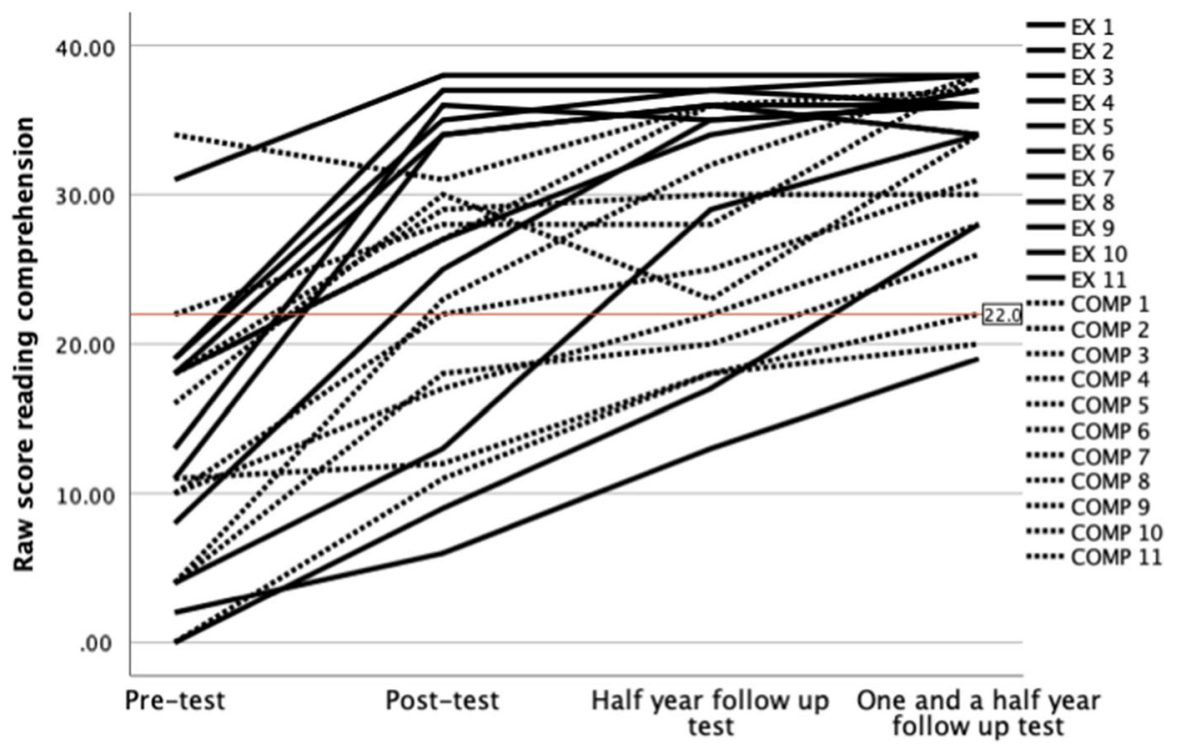

Test occasions

Fig. 6 Developmental trajectories for reading comprehension in the experimental and comparison groups

As shown in Fig. 6, we observed rapid development for most RtI students between the pre-and post-intervention periods, and this ability was sustained. Three of the RtI students exhibited slow development between the pre-and post-intervention periods. Although two of these students caught up, one was still below the cutoff point at the last follow-up assessment.

The cutoff point for a stanine score of 3 (demonstrated as a red line in Fig. 6) was determined according to the typically expected performance for grade 3 students, and these students were in grade 4 at the time of the one-and-a-half-year follow-up test. The distribution of the data from the comparison group shows a more scattered development pattern.

\section{Teacher impressions of the RtI model: descriptive data}

The RtI model was successful, according to the teachers. They believed that the students were closely monitored and that students at risk of falling behind received quick, intensive, and carefully balanced interventions if needed. They also claimed that they felt they had good control over the students' development.

I think early identification of students at risk ensures that no one falls behind.

I think [with the model] you can identify those who need help. I think that seems to be a huge advantage with the model. And then the same thing here, 
[...] when you conduct the group interventions, it seems to give good ... results. Teacher 1

The teachers highlighted the value of the repeated collaborative teacher meetings. They felt that these enabled teachers to discuss the methods and materials used in the interventions as they adjusted to teaching to meet the different needs of students.

... a thing that I thought was very useful, it was that we had meetings when you got to sit and discuss. That you actually get to sit and talk about these educational issues. Because that is usually rarely the case ... What do you do in your teaching? But also to get feedback on methods and ... yes there is something else I can do, get some new tips and ideas and perspectives. Teacher 2

The teachers stated that although the method might be perceived as resourceintensive because the students received intensive instruction during their early school years, the time spent represented a good investment that could counteract student failure in the future.

$\ldots$, it is resource-demanding [...] a cost. It is very expensive, and you have to consider that. But more resources early are good because I think we save [resources] in the long run ...

Special needs teacher

The teachers also mentioned that the model was, to some extent, inflexible because the students had to go through all three tiers. They asked for a more flexible RtI model in which a student could move directly from Tier 1 to Tier 3 if they had greater difficulties than their peers or had difficulties focusing or cooperating with peers in the Tier 2 setting.

The model seems a bit rigid to me, in that it has to be a small group first and then [the student can] move on to one-on-one [instruction]. [...] My experience is that usually, the [student's] needs are not just about reading but also difficulty concentrating. Because there you have a student who has difficulties focusing on his own reading and has a very hard time waiting for his turn and then does not let the other students finish reading or work, so [...] it affects, of course, the other students in the group. And that's probably where I can see that it might have been an advantage for the whole small group to have tutored that student one-to-one in Tier 3 directly. Teacher 1

\section{Discussion}

The present study examined the efficacy of a full-scale RtI model implemented in a Swedish school context compared to TAU. The aim was to examine whether the RtI model, which included identifying at-risk students and appropriate interventions, could enhance decoding and reading comprehension in students at risk of developing reading difficulties. Our findings are promising regarding the efficacy of the 
RtI model in Sweden. However, results must be interpreted with caution due to the small sample size and non-significant reading comprehension and sight word reading results. The model could probably be used to ensure that "no child is left behind" because its framework involves closely monitoring the development of basic skills with standardized tests and carefully evaluating the intervention effects. Our findings indicate that the RtI model can effectively identify and provide assistance to students who are at risk of developing reading difficulties. Indeed, our results from the RtI group show that fewer students needed support after the interventions and that their improved reading ability was well maintained in follow-up tests, whereas the performance in the comparison group actually declined more (ten scores in mean) between post-intervention and follow-up tests (see Table 1). Our study benefits from collected follow-up data as long-term effects can be analyzed. The sustained positive results in follow-up tests could be a long-term effect of early identification and intervention in the RtI-experimental condition, which is promising. However, this should at the same time be interpreted with carefulness since 1.5 years is a long time between post-test and follow-up, and differences at follow-up may also be attributable to factors outside of the experiment. In addition, the result is based on an arbitrary cutoff and a low number of participants. Nevertheless, our result is similar to those of previous studies that implemented the RtI model in other contexts; that is, the RtI model appears to reduce the number of students with reading difficulties compared with TAU (Burns et al., 2005; Grosche \& Volpe, 2013).

To some extent, the RtI program content involved "more of the same" Tier 1 efforts in Tier 2, but with additional time and more individualized instruction. In Tier 3, the one-to-one instruction was even more carefully tailored to each student's unique needs. For several students, Tier 3 one-to-one instruction was essential. Specifically, Tier 3 instruction was effective for at least two struggling students in this study. This is consistent with previous research (Denton et al., 2013; Noe et al., 2014). When assessed in the follow-up tests, only one of 11 RtI students needed extra support for reading comprehension after completing Tiers 1-3.

Our data show that the RtI group experienced more favorable development in all three variables (decoding, non-word reading, and reading comprehension) than students in the comparison group who underwent TAU. The effect size ranged from 0.49 to 1.00 , which reflects a moderate to high effect. However, it should be noticed that the differences in the reading comprehension and sight word reading measure were not statistically significant. The non-word reading test was significant when a one-tailed t-test was used. Since a positive result on the non-word reading test was expected, a one-tailed t-test might be more appropriate to avoid type II errors. The rationale for this is that the intervention includes training that targeted the grapheme-phoneme correspondence (Castles et al., 2018), which is highly highlighted by the non-word reading test. The 11 students in the RtI group met the cutoff criteria to a greater extent. Although the group data on decoding ability showed that students in the comparison group reached an acceptable level, analysis of individual students displayed that more students in the comparison group were substantially below the cutoff level.

However, the most notable difference between the RtI group and the comparison group was the distribution of the test results. Regardless of the outcome assessed, 
the standard deviation distribution in the RtI group was smaller than that in the comparison group. This result strengthens the conclusion that the RtI model may help to ensure that "no child is left behind." Previous studies in other countries also indicate that the RtI model facilitates the "no child left behind" vision (Fuchs et al., 2003; Grosche \& Volpe, 2013). However, this study is the first to deliver preliminary positive indications of the efficacy of the RtI model in a Swedish school setting. The students in the comparison group were expected to develop their skills in response to regular teaching in an ordinary classroom setting. It may have been more difficult to identify students with reading difficulties in the comparison group and provide appropriate interventions. Indeed, some students in the comparison group performed worse than their peers on non-word reading. This may indicate a shortcoming with the TAU. The students in the TAU condition did not receive explicit instruction about letter-sound correspondence and specific decoding training. This represents a difference between the reading instruction provided in the RtI experimental and comparison groups and could partly explain the between-group differences in outcome.

The teachers reported that in the RtI model, no student with difficulties remained unidentified and that the students quickly received intensive instruction, which helped in most cases. The interventions were increasingly tailored to the specific needs of students as the tier level increased (see "Method" section). However, the teachers suggested that the RtI model could have been more flexible. A more flexible framework would have enabled students with difficulty learning in a group to be referred directly from Tier 1 to Tier 3 interventions. This was also suggested by Compton et al. (2012) and Al Otaiba et al. (2014), who proposed that some children could be accurately identified as eligible for Tier 3 interventions using only Tier 1 data, which would avoid continued periods of failed instruction. The teachers in the present study emphasized the importance of collaborations between teachers and special needs teachers to modify the interventions to meet each student's specific needs. The importance of this collaboration has also been proposed in previous research (Dulaney, 2013). However, the RtI model requires more interventions and effort than TAU and consequently is more resource-intensive. This factor must be considered in the implementation of the RtI strategy. Indeed, many students in the comparison group developed normally as a result of TAU, which is less resource-intensive, and most students reached the cutoff point.

Nevertheless, the teachers stated that even if the RtI model is demanding in terms of resources, they considered it a good investment to counteract student failure. The risk of TAU is that students with reading difficulties may "fall between the cracks" and remain unidentified or are offered insufficient support and interventions. The cost of intensive interventions to prevent reading difficulties during the early school years may be balanced by the cost of assisting students who fail later on in public school, with important implications for education and overall life success. Accordingly, the use of the RtI model may be a preventive and proactive strategy in contrast to education systems in which students must fail before measures and support are offered (i.e., a "wait-to-fail" 
approach) (Fuchs \& Fuchs, 2006). Intensive support in later school years is also associated with high costs (Government Offices of Sweden, 2017).

\section{Study implications}

The present findings indicate that implementing the RtI model may enhance the Swedish school system by providing a logical framework for monitoring and delivering interventions to prevent reading difficulties in at-risk students. However, more rigorous research is needed.

Standardized tests are not built into the evaluation of basic student skill development in the "reading-writing-counting guarantee" (Skolverket, 2019a) or the Swedish national assessment follow-up system (Skolverket, 2019b). In the national assessment system, the evaluation of student reading development is based on teacher observations and assessment support materials. Thus, decisions about which students need support may be somewhat subjective. The efficiency of pedagogical methods or interventions cannot be confidently evaluated using qualitative assessments. Combining the national qualitative assessment with a standardized reading test could provide teachers with more comprehensive and confident data on students' reading development.

Consistent with previous international studies (Gersten et al., 2020; Wanzek et al., 2013, 2018), our data indicate that monitoring, along with adjusted, intensive, and individualized reading interventions, improved students' reading abilities in a Swedish school context. The RtI model contains a systematic framework for identifying at-risk students and the provision of appropriate interventions, which supports teachers and special needs teachers in their daily work.

\section{Limitations and future directions for research}

One study limitation was that our sample was relatively small. Thus, the findings should be interpreted with caution. However, this study is somewhat unique, as few studies have examined the implementation of a full-scale RtI model. Regarding confidence in the results of the one-and-a-half-year follow-up, outcomes may have been affected by factors external to the study. It is possible that sampling students from two different schools, in the same school district, to experimental or comparison conditions could have influenced the study result. However, the students were matched on both decoding ability and gender in a quasi-experimental design to account for this. In addition, it has been argued that students' prerequisites of learning in Swedish schools not only differ between schools but also within schools (Skolinspektionen, 2020b).

It could be argued that the Tier 2 and 3 intervention periods were too short; however, previous short-term RtI intervention studies have shown positive outcomes (Case et al., 2014; Pericola Case et al., 2010). Another limitation is that the only measure of intervention adherence was the logbook. Systematic observations of teachers' interventions would have increased fidelity but were infeasible owing 
to scarce recourses. Furthermore, our results indicated that the RtI framework has promise for the prevention and remediation of reading difficulties. Most students were above the cutoff levels after the RtI program.

Nevertheless, even when implementing the RtI model with extensive Tier 2 and 3 interventions, there may be a few students who do not "respond" to interventions (i.e., "non-responders"). In the present study, we identified two struggling students who did not fully respond to the Tier 2 and Tier 3 interventions; one of these students was still below the cutoff level in the follow-up tests. For such students, the school system (with a potential RtI framework) must offer some options for development after Tier 3. In the present RtI study, another tier, Tier 4, was implemented for two of the students still in need of support, starting in grade 3. The Tier 4 intervention focused on helping students to learn using assistive technology, such as "text-tospeech," to compensate for more resistant reading difficulties. The intention was to increase the students' independence and to facilitate the accumulation of knowledge. The results of these two students' progress through a four-tier RtI model will be presented in a forthcoming publication.

The main limitation of the present study was the small sample size. Therefore, studies with larger samples are necessary. Our research group plans to conduct a large-scale study to examine the RtI model in the Swedish school system. A more extensive study using more sophisticated statistical methods may provide more reliable results.

\section{Conclusion}

We observed positive effects for a RtI model implemented in a Swedish school context. Specifically, the number of students in need of support declined in the intervention group, compared with the TAU group. Analyzing the boxplot (Fig. 3) and the trajectories (Figs. 4, 5 and 6), we can conclude that the individuals in the RtI-group generally had a more favorable development on all three measures. The group distribution was greater in the comparison group, and more students were below the cutoff level. However, in the statistical group analysis, only the non-word one-and-ahalf-year Follow-Up reading measure was statistically significant using a one-tailed correction; thus, the between-group result must be interpreted with caution. One aspect that might have affected the result is the time limit between post and one-anda half-year follow-up; thus, other factors might have affected the results.

These findings are particularly compelling because the comparison group received a similar core reading program but no tiered approach to identify reading challenges and specialized instruction. Moreover, the teachers appreciated the RtI model because the students rapidly received customized support. Before the RtI model was implemented, almost half of the students scored below the cutoff level for at least one variable. However, after implementation, the number of students who needed special education services declined to one out of 11 . The teachers highlighted the success of the collaboration between teachers and special needs teachers and emphasized the need for a flexible RtI model. The teachers also perceived the model as resource-intensive. Further research with a larger sample is needed to 
examine the relative value of the RtI model in a Swedish school context. In addition, specialized reading interventions and assistive technology for non-responding students require further examination.

Acknowledgements This study is part of the Swedish National Research School Special Education for Teacher Educators (SET), funded by the Swedish Research Council (grant no. 2017-06039), for which we are grateful. We thank Sydney Koke, MFA, and Diane Williams, PhD, from Edanz Group (https://www. edanz.com/ac) for editing a draft of this manuscript.

Author contributions Both authors contributed to the study conception and design. Material preparation, data collection and analysis were performed by Camilla Nilvius and Idor Svensson. The first draft of the manuscript was written by Camilla Nilvius and Idor Svensson commented on previous versions of the manuscript. Both authors read and approved the final manuscript.

Funding Open access funding provided by Linnaeus University. This study is part of the Swedish National Research School Special Education for Teacher Educators (SET), funded by the Swedish Research Council (grant no. 2017-06039), for which the authors are grateful.

\section{Declarations}

Conflict of interest The authors have no conflict of interests to report.

Ethical approval The present study received ethical approval from Etikprövningsnämnden [Ethical Review Board], before the start of the project (D.nr 2017/412-31).

Open Access This article is licensed under a Creative Commons Attribution 4.0 International License, which permits use, sharing, adaptation, distribution and reproduction in any medium or format, as long as you give appropriate credit to the original author(s) and the source, provide a link to the Creative Commons licence, and indicate if changes were made. The images or other third party material in this article are included in the article's Creative Commons licence, unless indicated otherwise in a credit line to the material. If material is not included in the article's Creative Commons licence and your intended use is not permitted by statutory regulation or exceeds the permitted use, you will need to obtain permission directly from the copyright holder. To view a copy of this licence, visit http://creativecommons.org/licen ses/by/4.0/.

\section{References}

Al Otaiba, S., Folsom, J. S., Schatschneider, C., Wanzek, J., Greulich, L., Meadows, J., ... Connor, C. M. (2011). Predicting first-grade reading performance from kindergarten response to Tier 1 instruction. Exceptional Children, 77(4), 453-470.

Al Otaiba, S., Connor, C. M., Folsom, J. S., Wanzek, J., Greulich, L., Schatschneider, C., \& Wagner, R. K. (2014). To wait in Tier 1 or intervene immediately. Exceptional Children, 81(1), 11-27.

Balu, R., Zhu, P., Doolittle, F., Schiller, E., Jenkins, J., \& Gersten, R. (2015). Evaluation of response to intervention practices for elementary school reading. Retrieved May 15, 2020, from http://ies.ed. gov/ncee/pubs/20164000/pdf/20164000.pdf

Bjorn, P. M., Aro, M., Koponen, T., Fuchs, L. S., \& Fuchs, D. (2018). Response-to-intervention in Finland and the United States: Mathematics learning support as an example. Frontiers in Psychology, 9 , 800. https://doi.org/10.3389/fpsyg.2018.00800

Burns, M. K., Appleton, J. J., \& Stehouwer, J. D. (2005). Meta-analytic review of responsiveness-tointervention research: Examining field-based and research-implemented models. Journal of Psychoeducational Assessment, 23(4), 381-394. https://doi.org/10.1177/073428290502300406 
Case, L., Speece, D., Silverman, R., Schatschneider, C., Montanaro, E., \& Ritchey, K. (2014). Immediate and long-term effects of Tier 2 reading instruction for first-grade students with a high probability of reading failure. Journal of Research on Educational Effectiveness, 7(1), 28-53. https://doi.org/10. 1080/19345747.2013.786771

Castles, A., Rastle, K., \& Nation, K. (2018). Ending the reading wars: reading acquisition from novice to expert. Psychological Science in the Public Interest, 19(1), 5-51. https://doi.org/10.1177/15291 00618772271 lovett

Cirino, P. T., Rashid, F. L., Sevcik, R. A., Lovett, M. W., Frijters, J. C., Wolf, M., \& Morris, R. D. (2002). Psychometric stability of nationally normed and experimental decoding and related measures in children with reading disability. Journal of Learning Disabilities, 35(6), 526-539.

Clarke, B., Doabler, C. T., Smolkowski, K., Baker, S. K., Fien, H., \& Strand Cary, M. (2016). Examining the efficacy of a Tier 2 kindergarten mathematics intervention. Journal of Learning Disabilities, 49(2), 152-165. https://doi.org/10.1177/0022219414538514

Clarke, B., Smolkowski, K., Baker, S., Fien, H., Doabler, C., \& Chard, D. (2011). The impact of a comprehensive Tier I core kindergarten program on the achievement of students at risk in mathematics. The Elementary School Journal, 111(4), 561-584. https://doi.org/10.1086/659033

Compton, D. L., Gilbert, J. K., Jenkins, J. R., Fuchs, D., Fuchs, L. S., Cho, E., Eunsoo, B., Barquero, L. A., \& Bouton, B. (2012). Accelerating chronically unresponsive children to Tier 3 instruction: What level of data is necessary to ensure selection accuracy? Journal of Learning Disabilities, 45(3), 204-216. https://doi.org/10.1177/0022219412442151

Denton, C. A. (2012). Response to intervention for reading difficulties in the primary grades: Some answers and lingering questions. Journal of Learning Disabilities, 45(3), 232-243. https://doi.org/ 10.1177/0022219412442155

Denton, C. A., Fletcher, J. M., Taylor, W. P., Barth, A. E., \& Vaughn, S. (2014). An experimental evaluation of guided reading and explicit interventions for primary-grade students at-risk for reading difficulties. Journal of Research on Educational Effectiveness, 7(3), 268-293.

Denton, C. A., Tolar, T. D., Fletcher, J. M., Barth, A. E., Vaughn, S., \& Francis, D. J. (2013). Effects of Tier 3 intervention for students with persistent reading difficulties and characteristics of inadequate responders. Journal of Educational Psychology, 105(3), 633-648. https://doi.org/10.1037/a0032581

Dulaney, S. K. (2013). A middle school's response-to-intervention journey: Building systematic processes of facilitation, collaboration, and implementation. NASSP Bulletin, 97(1), 53-77. https://doi. org/10.1177/0192636512469289

Elwér, A., Fridolfsson, I., Samuelsson S., \& Wiklund, C. (2016). LäSt. Linköping.

Fälth, L., Gustafson, S., Tjus, T., Heimann, M., \& Svensson, I. (2013). Computer-assisted interventions targeting reading skills of children with reading disabilities - a longitudinal study. Dyslexia, 19(1), 37-53.

Felth Sjölund, I. (2012). Diamantjakten lärarhandledning. (1. uppl.). Natur \& Kultur.

Francis, D. J., Shaywitz, S. E., Stuebing, K. K., Shaywitz, B. A., \& Fletcher, J. M. (1996). Developmental lag versus deficit models of reading disability: A longitudinal, individual growth curves analysis. Journal of Educational Psychology, 88(1), 3-17. https://doi.org/10.1037/0022-0663.88.1.3

Fuchs, D., Compton, D., Fuchs, L., Bryant, J., \& Davis, G. (2008). Making "secondary intervention" work in a three-tier responsiveness-to-intervention model: Findings from the first-grade longitudinal reading study of the national research center on learning disabilities. Reading and Writing, 21(4), 413-436. https://doi.org/10.1007/s11145-007-9083-9

Fuchs, D., \& Fuchs, L. S. (2006). Introduction to response to intervention: What, why, and how valid is it? Reading Research Quarterly, 41(1), 93-99. https://doi.org/10.1598/rrq.41.1.4

Fuchs, D., \& Fuchs, L. S. (2017). Critique of the national evaluation of response to intervention: A case for simpler frameworks. Exceptional Children, 83(3), 255-268.

Fuchs, D., Mock, D., Morgan, P. L., \& Young, C. L. (2003). Responsiveness-to-intervention: Definitions, evidence, and implications for the learning disabilities construct. Learning Disabilities Research and Practice, 18(3), 157-171.

Gersten, R., Compton, D., Connor, C. M., Dimino, J., Santoro, L., Linan-Thompson, S., ... Hallgren, K. (2009). Assisting students struggling with reading: Response to intervention and multi-tier intervention in the primary grades. U.S. Department of Education, National Center for Education Evaluation and Regional Assistance, Institute of Education Sciences.

Gersten, R., Haymond, K., Newman-Gonchar, R., Dimino, J., \& Jayanthi, M. (2020). Meta-analysis of the impact of reading interventions for students in the primary grades. Journal of Research on Educational Effectiveness, 13(2), 401-427. https://doi.org/10.1080/19345747.2019.1689591 
Gilbert, J. K., Compton, D. L., Fuchs, D., Fuchs, L. S., Bouton, B., Barquero, L. A., \& Cho, E. (2013). Efficacy of a first-grade responsiveness-to-intervention prevention model for struggling readers. Reading Research Quarterly, 48(2), 135-154. https://doi.org/10.1002/rrq.45

Gough, P. B., \& Tunmer, W. E. (1986). Decoding, reading, and reading disability. Remedial and Special Education (RASE), 7(1), 6-10.

Government Offices of Sweden (2017). Läsa, skriva, räkna - en åtgärdsgaranti [Elektronisk resurs] [Read, write, count - a guarantee of action]. Retrieved June 6, 2020, from http://www.regeringen.se/ rattsdokument/proposition/2017/09/prop.-20171818/

Grosche, M., \& Volpe, R. J. (2013). Response-to-intervention (RTI) as a model to facilitate inclusion for students with learning and behaviour problems. European Journal of Special Needs Education, 28(3), 1-16. https://doi.org/10.1080/08856257.2013.768452

Häggström, I., \& Frylmark, A. (2010). Trugs. Teach reading using games. Träna läsning med spel. Storvreta: OrdAF.

Hill, D. R., King, S. A., Lemons, C. J., \& Partanen, J. N. (2012). Fidelity of implementation and instructional alignment in response to intervention research. Learning Disabilities Research \&amp; Practice, 27(3), 116-124. https://doi.org/10.1111/j.1540-5826.2012.00357.x

Kerins, M. R., Trotter, D., \& Schoenbrodt, L. (2010). Effects of a Tier 2 intervention on literacy measures: Lessons learned. Child Language Teaching and Therapy, 26(3), 287-302.

Natur \& Kultur. (2020). Läshoppet [Readingjump]. Retrieved June 6, 2020, from https://www.nok.se/ titlar/laromedel-b1/lashoppet-lashoppet-niva-1/

Läsa, S., Räkna G. (2016). På goda grunder: En åtgärdsgaranti för läsning, skrivning och matematik: betänkande [On good grounds: a guarantee of action for reading, writing and mathematics: A report]. Wolters Kluwer.

Lovett, M. W., Frijters, J. C., Wolf, M., Steinbach, K. A., Sevcik, R. A., \& Morris, R. D. (2017). Early intervention for children at risk for reading disabilities: The impact of grade at intervention and individual differences on intervention outcomes. Journal of Educational Psychology, 109(7), 889.

Löwenbrand-Jansson, G. (2018). FonoMix, Munmetoden - Fonologisk multisensorisk läsinlärningsmetod [FonoMix, Mouth method - Phonological multisensory learning to read method]. Gullow Förlag.

Lundberg, I. (2001). Vilken bild är rätt? En enkel klassdiagnos av läsförståelse [Which image is correct? A simple class diagnosis of reading comprehension]. Natur \& Kultur.

Noe, S., Spencer, T. D., Kruse, L., \& Goldstein, H. (2014). Effects of a Tier 3 phonological awareness intervention on preschoolers' emergent literacy. Topics in Early Childhood Special Education, 34(1), 27-39. https://doi.org/10.1177/0271121413489172

Palinscar, A. S., \& Brown, A. L. (1984). Reciprocal teaching of comprehension-fostering and comprehension-monitoring activities. Cognition and Instruction, 1(2), 117-175.

Pericola Case, L., Speece, D. L., Silverman, R., Ritchey, K. D., Schatschneider, C., Cooper, D. H., ... Jacobs, D. (2010). Validation of a supplemental reading intervention for first-grade children. Journal of Learning Disabilities, 43(5), 402-417.

Rack, J. P., Snowling, M. J., \& Olson, R. K. (1992). The non-word reading deficit in developmental dyslexia: A review. Reading Research Quarterly, 29-53.

Reynolds, C. R., \& Shaywitz, S. E. (2009). Response to intervention: Ready or not? Or from wait-to-fail to watch-them-fail. School Psychology Quarterly, 24(2), 130-130. https://doi.org/10.1037/a0016158

SBU. (2014). Dyslexia in children and adolescents - tests and interventions. Stockholm: Swedish Council on Health Technology Assessment (SBU); 2014. SBU report no 225 (in Swedish). https://www. sbu.se/en/publications/sbu-assesses/dyslexia-in-children-and-adolescents--tests-and-interventions/

Scheltinga, F., van der Leij, A., \& Struiksma, C. (2010). Predictors of response to intervention of word reading fluency in dutch. Journal of Learning Disabilities, 43(3), 212-228. https://doi.org/10.1177/ 0022219409345015

Simmons, D. C., Coyne, M. D., Hagan-Burke, S., Kwok, O-M., Simmons, L., Johnson, C., ... Crevecoeur, Y. C. (2011). Effects of supplemental reading interventions in authentic contexts: A comparison of kindergarteners' response. Exceptional Children, 77(2), 207-228.

Skolinspektionen. (2014). Skolans arbete med extra anpassningar: [Elektronisk resurs] Kvalitetsgranskningsrapport [The school's work with extra adaptations: [Electronic resource] Quality review report] Stockholm. Retrieved June 6, 2020, from https:/www.skolinspektionen.se/sv/Tillsyngranskning/ Kvalitetsgranskning/Skolinspektionen-granskar-kvaliteten/skolans-arbete-med-extra-anpassningar/

Skolinspektionen. (2020a). Kartläggning och tidiga stödinsatser i förskoleklassen [Chart and early support measures in the preschool class]. Retrieved May 20, 2020, from https://skolinspektionen.se/ 
beslut-rapporterstatistik/publikationer/kvalitetsgranskning/2020/kartlaggning-och-tidiga-stodinsats er-i-forskoleklassen/

Skolinspektionen. (2020b). Resultatskillnader inom skolor [Differences in results within schools]. Retrieved August 21, 2021, from http://www.skolinspektionen.se/sv/Beslut-och-apporter/Publikatio ner/Granskningsrapport/Kvalitetsgranskning/resultatskillnader-inom-skolor

Skolverket. (2019a). Läsa, skriva, räkna - en garanti för tidiga stödinsatser [Read, write, count - a guarantee for early support efforts]. Retrived January 20, 2021, from https://www.skolverket.se/skolu tveckling/leda-och-organisera-skolan/organisera-tidigt-stod-och-extra-anpassningar/lasa-skrivarakna---garanti-for-tidiga-insatser

Skolverket. (2019b). Nationellt Bedömningsstöd i Läs- och skrivutveckling. Svenska och svenska som andraspråk $i$ årskurs 1-3 [National Assessment Support in reading and writing development. Swedish and Swedish as a second language in grades 1-3]. Retrived January 20, 2021, from https://bp. skolverket.se/delegate/download/test/informationmaterial?testGuid=06BB244CC6964A0394B4 CEE0FA9FC3E9

Stecker, P. M., Fuchs, D., \& Fuchs, L. S. (2017). Progress monitoring as essential practice within response to intervention. Rural Special Education Quarterly, 27(4), 10-17. https://doi.org/10.1177/ 875687050802700403

Svensson, I., \& Jacobson, C. (2006). How persistent are phonological difficulties? A longitudinal study of reading retarded children. Dyslexia, 12(1), 3-20.

Taube, K., Fredriksson, U., \& Olofsson, Å. (2015). Kunskapsöversikt om läs- och skrivundervisning för yngre elever: Delrapport från SKOLFORSK-projektet [Literature overview on reading and writing instruction for younger students: Interim report from the SKOLFORSK project]. Retrived May 20, 2020 from https://www.vr.se/download/18.2412c5311624176023d25b34/1555424813359/Kunsk apsoeversikt-om-laes-och-skrivundervisning-foer-yngre-elever_VR_2015.pdf

Vaughn, S., Denton, C. A., \& Fletcher, J. M. (2010). Why intensive interventions are necessary for students with severe reading difficulties. Psychology in the Schools, 47(5), 432-444. https://doi.org/10. 1002/pits.20481

Wanzek, J., Stevens, E. A., Williams, K. J., Scammacca, N., Vaughn, S., \& Sargent, K. (2018). Current evidence on the effects of intensive early reading interventions. Journal of Learning Disabilities, 51(6), 612-624. https://doi.org/10.1177/0022219418775110

Wanzek, J., \& Vaughn, S. (2008). Response to varying amounts of time in reading intervention for students with low response to intervention. Journal of Learning Disabilities, 41(2), 126-142. https:// doi.org/10.1177/0022219407313426

Wanzek, J., Vaughn, S., Scammacca, N., Gatlin, B., Walker, M. A., \& Capin, P. (2016). Meta-analyses of the effects of Tier 2 type reading interventions in grades K-3. Educational Psychology Review, 28(3), 551-576. https://doi.org/10.1007/s10648-015-9321-7

Wanzek, J., Vaughn, S., Scammacca, N. K., Metz, K., Murray, C. S., Roberts, G., \& Danielson, L. (2013). Extensive reading interventions for students with reading difficulties after grade 3. Review of Educational Research, 83(2), 163-195. https://doi.org/10.3102/0034654313477212

Wendick, G. (2018). IntensivLäsning - Upprepad läsning med strukturerade läslistor [Intensive Reading Repeated reading with structured reading lists]. Wendick Utbildning.

Publisher's Note Springer Nature remains neutral with regard to jurisdictional claims in published maps and institutional affiliations. 